\title{
A história social do português do Brasil e o preconceito linguístico
}

\section{The social history of Brazil's Portuguese and linguistic prejudice}

\author{
Silvana Silva de Farias Araújo² \\ Nilton Carlos Carmo Sousa ${ }^{3}$
}

Resumo: A ideia central deste texto gira em torno de questões sócio-históricas que estão na base da formação e da caracterização atual do português do Brasil (PB), a exemplo dos contatos linguísticos e dos processos tardios de urbanização e de escolarização. No decorrer do texto, discutimos como a sócio-história do PB gerou reflexos consideráveis na realidade sociolinguística brasileira, com sérias implicações nas práticas de ensino-aprendizagem de Língua Portuguesa nas escolas. Para discutir essas questões são focalizados temas da Sociolinguística (Variacionista e Educacional) e da Linguística do Contato. Concluímos que há um enraizamento social no preconceito linguístico, havendo variantes linguísticas "toleradas" no ambiente escolar, ainda que não sejam as formas padrão, e outras totalmente repudiadas, algo que perpassa pelas formulações teóricas labovianas, notadamente as que tratam dos indicadores, marcadores e estereótipos (LABOV, 2008[1972]).

Palavras-chave: História social do português do Brasil; Ensino de Língua Portuguesa; Preconceito linguístico.

Abstract: The central idea of this text revolves around socio-historical issues that are the basis of the formation and the current characterization of Brazilian Portuguese (PB), such as language contacts and late urbanization and schooling processes. In the course of the text, we discuss how the socio-history of PB generated considerable reflexes in Brazilian sociolinguistic reality, with serious implications in teaching-learning practices of Portuguese Language in schools. In order to discuss these issues, the topics of Sociolinguistics (Variationist and Educational) and Linguistics of the Contact are focused. We conclude that there is a social rootedness in linguistic prejudice, and there are linguistic variants "tolerated" in the school environment, even though they are not the standard forms, and others totally repudiates, something that runs through theoretical Labovian formulations, especially those dealing with stereotypes, markers and indicators (LABOV, 2008 [1972]).

Keywords: Social history of Brazil's Portuguese; Portuguese language teaching; Linguistic prejudice.

\section{Introdução}

\footnotetext{
${ }^{1}$ Este texto é dedicado a todos os nossos alunos que sempre nos instigaram e instigam a pensarmos a complexidade que é ensinar o português em um país com velhas concepções sobre o que é ser professor de Português. Salientamos ainda que o presente trabalho foi realizado com apoio da Coordenação de Aperfeiçoamento de Pessoal de Nível Superior - Brasil (CAPES) - Código de Financiamento 001. 2 Professora do Programa de Pós-Graduação em Estudos Linguísticos (PPGEL) da Universidade Estadual de Feira de Santana (UEFS). Pósdoutoranda, com bolsa PDJ/CNPq, desenvolvendo plano de trabalho sobre documentação de comunidades rurais afro-brasileiras na Bahia e em Sergipe, na Universidade Federal de Sergipe (UFS). E-mail: silvana.uefs.2014@gmail.com. ${ }^{3}$ Mestrando em Estudos linguísticos (PPGEL/UEFS/CAPES). E-mail: nccsousa@hotmail.com.
} 
O Brasil é um país onde, atualmente, o português é a língua majoritária, não sendo, obviamente, o único idioma falado em seu imenso território. Historicamente, sabemos que havia nesse país de dimensões continentais uma espécie de "babel linguística", cujos matizes eram pintados pelas diversas línguas indígenas e africanas que aqui conviveram em suas mais sinuosas relações com a língua portuguesa e, mais tarde, com as faladas pelos imigrantes europeus e asiáticos.

Paralelamente às diversas situações de contatos linguísticos ocorridos no Brasil, houve situações de conflitos das mais diversas ordens, dentre os quais se destacam, neste texto, os que envolvem questões ideológicas em torno da supremacia de uma língua ou de uma variedade em detrimento de outras.

No que diz respeito aos conflitos relacionados à hegemonia da língua portuguesa em relação a tantas outras que havia no Brasil, faz-se necessário entender a história social linguística brasileira. Em linhas gerais, defendemos que os conflitos linguísticos existentes hoje e ontem no espaço brasileiro só podem ser bem compreendidos quando há uma reflexão sobre o contexto sócio-histórico que possibilitou que uma cultura se tornasse hegemônica em relação a outras. Nesse sentido, é indispensável refletir sobre a vinda forçada de africanos escravizados - sob as mais cruéis ações humanas -, fato que se somou às mazelas cometidas para com os indígenas que habitavam o Brasil no período de criação da nação brasileira.

Assim, em um país em que políticas linguísticas não são prioritárias, a disciplina Língua Portuguesa só poderia ser alvo constante de críticas. Professores, linguistas, pedagogos, estudantes e pessoas de modo geral, frequentemente, abordam questões referentes ao artificialismo presente nas aulas desse componente curricular, criticando uma prática de ensino pouco produtiva para o desenvolvimento da competência comunicativa dos alunos, bem como uma prática que desconsidera e discrimina a realidade sociocultural dos educandos. Nessas discussões, apontam-se, por exemplo, a ênfase excessiva no ensino de uma gramática anacrônica e descontextualizada, bem como a tímida presença do texto nas salas de aula, o que leva a um ineficiente trabalho com a leitura e a escrita. Observa-se que tais discussões, em sua grande maioria, são fruto de pesquisas realizadas em escolas urbanas, sem se considerar as especificidades das escolas do campo, algo que pode ser revelador da pouca sensibilidade a uma pedagogia culturalmente sensível (BORTONI-RICARDO, 2005) e do desconhecimento das possibilidades de diálogo entre culturas e linguagens.

Feitas essas primeiras colocações, torna-se imperioso discorrer sobre alguns fatos da história social do português do Brasil que alicerçam os preconceitos e as atrocidades que se cometem atualmente nos mais diversos espaços brasileiros, a exemplo dos escolares. Assim, trazemos à tona, na próxima seção, algumas questões, como a colonização brasileira e o consequente contato entre línguas dela decorrente, o elitismo da sociedade "urbanocêntrica" e as raízes do preconceito social e linguístico brasileiro. 


\title{
A constituição e a caracterização atual do português brasileiro ${ }^{4}$
}

O português do Brasil tem origens que perpassam pelo chamado PE (português europeu). Sabese, entretanto, que, principalmente, nos três primeiros séculos de colonização do Brasil, o contato étnico entre portugueses, africanos e autóctones foi intenso, o que gerou nos termos de Mattos e Silva (1993, p. 77) um "multilinguismo generalizado".

Diante desse contexto de formação sócio-histórica do povo brasileiro e, consequentemente, do PB (português brasileiro), afirma-se que as variações e as mudanças linguísticas que acontecem nessa variedade da língua portuguesa podem ser explicadas com base no contato linguístico ${ }^{5}$. É claro que ainda existem relações entre PB e PE, mas as mudanças linguísticas não podem ser justificadas como fruto da evolução interna das línguas, desconsiderando o contexto sócio-histórico, pois, segundo Labov (1972 [1965] apud MATTOS E SILVA, 2008, p. 176), "a mudança linguística não pode ser explicada por argumentos puramente internos dentro do sistema; mesmo se externas, as relações sociolinguísticas são reconhecidas como fatores condicionadores adicionais".

A respeito da relação entre língua e sociedade, no que diz respeito à formação do $\mathrm{PB}$, é interessante compreender o contexto mais amplo, por isso, a seguir, a partir da citação de Lucchesi (2017, p. 349), será possível elucidá-lo, considerando os diferentes povos imbricados e suas respectivas línguas:

\begin{abstract}
Estima-se que mais de mil línguas indígenas eram faladas no território brasileiro no início do século XVI (Rodrigues 1993), e mais de duzentas línguas africanas foram introduzidas no país pelo tráfico negreiro, entre 1550 e 1850 (Petter 2006). Assim, durante quase dois séculos, o português foi apenas uma das muitas línguas faladas no território brasileiro. Porém, hoje cerca de $98 \%$ da população tem o português como língua materna, conquanto o Brasil seja também, e paradoxalmente, um dos países de maior diversidade linguística do planeta, com centenas de línguas indígenas pertencentes a cinco famílias tipologicamente diferenciadas (embora a maioria esteja em vias de desaparecimento) e dezenas de língua de imigração. Como toda essa diversidade linguística se concentra em apenas dois por cento de sua população (Lucchesi 2015a), justifica-se a definição de Mattos e Silva de "multilinguismo localizado". Portanto, a história sociolinguística do Brasil tem em seu cerne um violento processo de homogeneização linguística, embora a clivagem étnica que marca a formação da sociedade brasileira ainda se reflita em sua atual polarização sociolinguística (Lucchesi 2015b). (LUCCHESI, 2017, p. 349).
\end{abstract}

Diante desse contexto de formação sócio-histórica do português brasileiro, Lucchesi (2000; 2002; 2015) apresenta a tese de que o PB não é somente heterogêneo, mas polarizado. Segundo o autor, na realidade linguística brasileira, pode-se pensar em norma culta e norma popular. Como se viu, a norma popular é originada na aquisição "imperfeita" do português, por isso os seus utentes tendem a não seguir as regras da norma padrão. Os falantes da norma culta, por outro lado, que também não seguem todas as regras da norma padrão, são escolarizados e seus dialetos não são estigmatizados nem desprestigiados socialmente.

\footnotetext{
4 Alguns trechos e ideias presentes nesta e nas seções seguintes serão publicadas, posteriormente, na dissertação em andamento intitulada $A$ concordância verbal no continnum rural-urbano: uma análise sociolinguística da fala de estudantes do município de Tucano-BA (SOUSA, no prelo), financiada pela CAPES.

${ }^{5}$ Os linguistas que defendem a teoria da deriva linguística, por outro lado, tentam explicar as variações e as mudanças linguísticas, defendendo a ideia de que há uma predeterminação para elas acontecerem, encarando o contato como um fator que aligeirou as mudanças e não como um fator condicionador para elas acontecerem (NARO; SCHERRE, 2007).
} 
Ainda de acordo com Lucchesi (2002), "o termo NORMA comporta, como já foi enfatizado pela literatura existente, dois conceitos distintos (cf., por exemplo, Alain Rey, 1972).": o conceito que trata da ideia do que é normativo, uma regra a ser seguida; e o conceito do que é normal, espontâneo. Essa questão é pensada por Lucchesi (2002), que destaca a divisão normas objetiva e subjetiva. As normas culta e popular, por representarem a fala real das pessoas, figuram no grupo da norma objetiva, por sua funcionalidade, enquanto a norma padrão pertence ao grupo da norma subjetiva, uma vez que se refere ao normativo que não é seguido pelos falantes de uma comunidade de fala.

Nesse contexto, a partir dessa breve contextualização sobre a formação sócio-histórica do português brasileiro, bem como da polarização linguística, na próxima, discutem-se o contato entre línguas, importante fator para a formação do PB, e o processo de escolarização no Brasil.

\section{O contato linguístico e o processo de escolarização no Brasil: breves considerações}

A visão de que as variações que ocorrem no PB podem ser explicadas pela formação sóciohistórica da língua, no que tange, sobretudo, à questão do contato e à forma como os africanos trazidos à força para o Brasil adquiriram o português é fortemente defendida por Lucchesi (1999; 2001; 2002; 2009; 2015; 2017). Além dele, outros tantos pesquisadores defendem essa tese, como, por exemplo, Mattos e Silva (2001).

Segundo Lucchesi (2015, p. 93), "apesar de reunir condições sócio-históricas, em princípio, muito propícias à crioulização da língua do colonizador europeu, não ocorreu no Brasil um processo estável, duradouro e representativo de crioulização da língua portuguesa.", isto é, os filhos de falantes das línguas africanas aprenderam o português como $L 1$, língua segunda de seus pais, mas não criaram uma gramática original, como acontece nos casos de crioulização. (ROUGÉ, 2008 apud LUCCHESI, 2015, p. 94). Dessa forma, constata-se que o contato linguístico contribuiu e contribui para as variações e mudanças no PB, a exemplo da mudança no paradigma verbal, mas não se pode dizer que é apenas essa questão sóciohistórica que condiciona a mudança, haja vista existirem condicionadores internos também, além de outros fatores socioculturais.

Dando continuidade à discussão sobre a história do contato linguístico no Brasil, Lucchesi (2015) aponta que esse processo provocou a polarização sociolinguística do PB. Segundo o autor, houve, inicialmente, a polarização entre português e línguas gerais indígenas, visto que os índios foram os primeiros a serem escravizados pelos colonizadores. Depois, houve a polarização entre português e línguas africanas, sobretudo as línguas da família banto. E, em seguida, a polarização entre português e suas variedades defectivas faladas por índios e africanos. Atualmente, a polarização se dá entre as variedades cultas do $P B$, faladas por pessoas altamente escolarizadas, e as variedades populares, faladas por pessoas pouco ou não escolarizadas.

A partir desse contexto, pensando nas normas cultas e populares, respectivamente, pode-se dizer que há duas histórias que lançam luzes para a discussão sobre a formação e estágio atual dessas normas: a história da escolarização no Brasil e a história do contato linguístico. A seguir, aborda-se, brevemente, a história da escolarização. 
Sabe-se que, mesmo atualmente, o Brasil possui baixos índices de educação. No início da colonização e, posteriormente, no Império, não foi diferente. As diferenças no campo educacional entre Brasil e Portugal eram bastante significativas e talvez por isso haja um fosso tão grande entre a norma culta (aprendida na escola) e a norma popular (adquirida na infância). Segundo Araujo (2005, p. 34), o déficit na educação, atualmente, deve ser "um reflexo das políticas educacionais elitistas vigentes no Brasil, desde os inícios de sua colonização.".

Compreende-se que a escolarização é um fator importante para o domínio da norma culta, o que permite afirmar que a ausência de escolarização acarretou uma variedade diferente do português europeu, gerando, dessa forma, as variedades populares, hoje faladas por pessoas pouco escolarizadas e com poucos recursos sociais e financeiros. Por outro lado, a elite da Colônia e do Império, representantes da variedade do português de Portugal, vindos para o Brasil em busca de mais riquezas, quando aqui tiveram seus filhos, estes receberam, em grande medida, educação e adquiriram a variante culta da língua.

Assim, é preciso considerar que a história da educação no Brasil não foi e não é democrática, basta pensarmos no contexto apresentado no parágrafo anterior e refletir sobre as reais condições da educação pública, hoje, no Brasil.

Segundo Geraldi (1991 apud MATTOS E SILVA, 2017 [1995], p. 32-33),

\begin{abstract}
Antigamente, os professores eram da 'elite' cultural e os alunos, da 'elite' social; os alunos aprendiam, apesar das evidentes falhas didáticas; aprendiam muito com professores altamente capazes por vocação e, sobretudo, pelas condições favoráveis, saúde, alimentação, farta possibilidade de leitura. Nos anos 1970-1980, o crescimento da população escolar nas escolas públicas do Estado de São Paulo foi da ordem de um milhão e meio de crianças. Esse crescimento foi um primeiro resultado da política educacional implantada no período que sucedeu a revolução de 64 em nosso país e que, ampliando o número de anos de escolaridade a um contingente da população, pretendeu fazer passar a idéia de uma educação que se 'democratizava', porque fazia aumentar as chances de igualdade de condições. $O$ aumento do número de estudantes exigiu, em contrapartida, maior quantidade de professores. Onde buscá-los?
\end{abstract}

A democratização do ensino é, pois, na verdade, a pseudodemocratização, uma vez que as escolas passaram a receber, a matricular os alunos, e a educação, que até então funcionava relativamente bem, deixou de funcionar, pois a preocupação passou a ser, na maioria das vezes, com a quantidade em vez da qualidade. Além disso, onde encontrar tantos professores capacitados? Segundo Mattos e Silva (2017 [1995], p. 34), "As escolas que nos tempos que correm são "pensadas para o povo", tornam-se, de fato, contra o povo, uma vez que o fracasso está diretamente correlacionado à origem social.". Ou seja, mesmo com a mudança dos regimes no Brasil, continua-se "reproduzindo o mesmo sistema de oligarquias dominantes, que detêm os mesmos direitos, em desaproveito dos outros, mesmo que mudados os senhores." (MATTOS E SILVA, 2017 [1995], p. 34-35).

Enfim, ter acesso à educação formal não significa dizer que é ter a mesma oportunidade de aprendizagem, haja vista existir um déficit proeminente na educação pública brasileira e, por outro lado, existirem escolas particulares trabalhando em favor da educação dos filhos da elite brasileira contemporânea.

Correlacionar questões educacionais a questões sobre a história sociolinguística brasileira tem levado a importantes resultados. Nesse sentido, os princípios teórico-metodológicos da Sociolinguística 
Educacional (BORTONI-RICARDO, 2004; 2005) e também do modelo proposto por Bortoni-Ricardo (2005) para o estudo do português brasileiro (PB), centrando a discussão no continnum rural-urbano, são muito pertinentes para se entender a realidade sociolinguística brasileira. Essa questão é abordada na seção seguinte.

\title{
A realidade sociolinguística brasileira vista sob a ótica dos três continua
}

Os continua propostos por Bortoni-Ricardo (2005), para Faraco (2008, p. 44), representam o modelo mais adequado para o registro da diversidade linguística brasileira. Segundo o autor, a teorização de Bortoni-Ricardo (2005) vai além dos cortes dicotômicos já realizados, como "português culto/português popular" (FARACO, 2008, p. 44) e, por isso, se aproxima mais da tentativa de dar conta da realidade linguística brasileira.

No que se refere aos continua, são eles: de urbanização ou rural-urbano, de oralidade-letramento e de monitoração estilística. Referente ao continnum rural-urbano, Bortoni-Ricardo (2005) argumenta que numa linha imaginária há duas extremidades: num extremo se encontram as variedades rurais isoladas; no meio da linha, uma área rurbana (onde coabitam os dialetos rurais e urbanos) e no outro extremo, as variedades urbanas padronizadas. A citação seguinte melhor explicita essa afiramção:

\begin{abstract}
Enquanto os falares rurais ficavam muito isolados pelas dificuldades geográficas de acesso, como rios e montanhas, e pela falta de meios de comunicação, as comunidades urbanas sofriam a influência de agências padronizadoras da língua, como a imprensa, as obras literárias e, principalmente, a escola. Nas cidades também se desenvolvia o comércio e, depois, a indústria; ali se instalavam as repartições públicas civis e militares, as organizações religiosas e outras instituições sociais que são depositárias e implementadoras de culturas de letramento. (BORTONI-RICARDO, 2004, p. 51-52).
\end{abstract}

Como é possível perceber, as comunidades rurais não tiveram condições propícias de acesso à norma culta da língua. Com a globalização, esse panorama se modificou e hoje as comunidades rurais estão, em sua maioria, expostas às mídias e seus moradores frequentam as escolas, instituições formais do ensino de língua. De qualquer forma, mesmo tendo havido modificações no panorama elencado pela autora na citação acima, não se pode apagar o que foi vivido por essas comunidades rurais e, simplesmente, argumentar a favor da padronização linguística em comunidades rurais e urbanas, obrigando as pessoas a seguirem todas as suas normas gramaticais. Por isso, é fundamental compreender as variações, sejam lexicais, morfossintáticas, de qualquer ordem, que se apresentam nessas comunidades e perceber, ainda, a influência das questões sócio-históricas para a língua nas comunidades, isto é, discutir questões socioculturais que estão diretamente ligadas às questões linguísticas.

A respeito do continnum oralidade-letramento, Bortoni-Ricardo (2004) destaca, na linha imaginária, que, numa extremidade há os eventos de oralidade, que nada têm a ver com as influências da escrita, e na outra, os eventos de letramento, que são pautados nas influências da escrita. De acordo com a autora, "não existem fronteiras bem marcadas entre os eventos de oralidade e de letramento" (BORTONI-RICARDO, 2004, p. 62) e que um evento que é, originalmente, considerado de letramento, isto é, que se pauta em textos escritos, "pode ser permeado de minieventos de oralidade" (BORTONIRICARDO, 2004, p. 62). 
No que diz respeito ao continnum de monitoração estilística, Bortoni-Ricardo (2004) argumenta sobre menos monitoração e mais monitoração, que são os dois constituintes da linha imaginária desse continnum. Segundo a autora, há situações que "exigem muita atenção do falante" (BORTONI-RICARDO, 2004, p. 62), o que demarca mais monitoração e que estão diretamente ligadas ao ambiente, ao interlocutor e ao tópico da conversa, fatores que desencadeiam a monitoração do estilo.

Dessa maneira, compreendendo a importância dos três continua propostos por Bortoni-Ricardo (2005), vale destacar que eles se entrecruzam (FARACO, 2008), à medida que, numa análise, é possível perceber se a fala de um determinado informante é mais rural ou mais urbana, se é mais letrada ou mais oral e, ainda, se é mais monitorada ou menos monitorada. Esse trabalho é realizado, inclusive, por Bortoni-Ricardo (2004, p. 64), a partir de dados coletadas em Brazlândia.

Nesse sentido, detendo-nos mais no continnum rural-urbano, cabe salientar que como se sabe, a urbanização no Brasil aconteceu tardiamente se comparada à de países da Europa, que deram início a esse processo no final da Idade Média, adiantando-o no século XVII e consolidando-o no século XIX (BORTONI-RICARDO, 2011[1985], p. 11). A autora, apoiando-se em dados do IBGE, argumenta que, no Brasil, porém, a urbanização é impulsionada a partir do século XX, levando a população brasileira que, até a década de 1950, era predominantemente rural, passasse a ser prioritariamente urbana a partir da década de 1980.

Assim, com o crescente fluxo de migração do campo para a cidade, nota-se que o país começa a deixar de ser rural para se tornar urbano. Sem dúvida, a falta de políticas voltadas ao campo contribuiu para o intenso fluxo migratório e para a falsa ideia de que o meio rural é um espaço sem perspectiva de futuro, predestinado, portanto, a desaparecer.

Diante dessa transformação social, a língua também sofreu interferências, visto que houve a institucionalização da língua portuguesa, a estratificação social do Brasil Colônia e o processo de urbanização. Esses aspectos são elucidados por BortoniRicardo (2011, p. 30) como fatores que podem explicar o fenômeno da padronização da língua no Brasil, além, é claro, do fator demográfico.

A respeito da padronização da língua, Bortoni-Ricardo (2011, p. 32) salienta sua coocorrência com o processo de urbanização, uma vez que, com a chegada da corte portuguesa ao Rio de Janeiro, houve não só o desenvolvimento da cidade, mas "a difusão da língua padrão e da cultura cosmopolita", mostrando que "o acesso à leitura e à escrita correu paralelo no Brasil ao processo de urbanização" (BORTONI-RICARDO, 2011, p. 33). 
Assim, nota-se, de fato, a relevância em discutir o continnum rural-urbano, haja vista a urbanização ser um excelente mote para tratar de mudanças sociais e, consequentemente, linguísticas.

De acordo com os parâmetros do Instituto Brasileiro de Geografia e Estatística (IBGE) (apud BORTONI-RICARDO, 2005, p. 92), "toda sede de município ou distrito, independentemente do tamanho e das características das atividades produtivas de sua população" é considerada uma área urbana. Se considerados esses critérios, todos os municípios brasileiros são zonas urbanas. Entretanto, é válido ponderar e lançar mão dos parâmetros estabelecidos pela Organização de Cooperação e Desenvolvimento Econômico (OCDE) os quais estabelecem que para um município ser considerado urbano deve "apresentar uma densidade demográfica de 150 habitantes $/ \mathrm{km}^{2}$ e uma população nunca menor que 50 mil habitantes.” (BORTONI-RICARDO, 2005, p. 92).

Nesse sentido, devemos considerar que há municípios urbanos que mantêm fortes relações com o campo, o que nos faz pensar nas comunidades "rurbanas", que, em linhas gerais, podem ser entendidas como comunidades que, apesar de estarem localizadas em espaços urbanos, os seus membros cultivam hábitos rurais, dentre esses, traços linguísticos típicos de moradores de áreas rurais. Desse modo, devemos pensar que o delineamento rural $x$ urbano não se esgota na divisão temporal da mobilidade geográfica acelerada no século XX, pois como assinalam Ribeiro e Lacerda (2013, p. 95), “A divisão também é social, e, até hoje, há comunidades rurais que não se urbanizaram, que continuam no ritmo colonial. E isso não ocorre só no "sertão", em virtude do isolamento geográfico; isso também é motivado pelo isolamento social [...]”. Sobre essa questão, temos que refletir sobre a natureza das variantes linguísticas, a fim de pensarmos em classificar um falar como "rural" ou "urbano".

\section{O entrelaçamento: história social e preconceito linguístico no PB}

Referente ao valor social da variação, no que tange à relação entre língua e sociedade, Gnerre (1985, p. 4) afirma que "uma variedade linguística 'vale' o que 'valem' na sociedade os seus falantes, isto é, vale como reflexo do poder e da autoridade que eles têm nas relações econômicas e sociais." Assim, percebe-se que a variação diastrática está diretamente ligada ao poder da linguagem, ou melhor, ao poder de quem emite a linguagem, uma vez que os sujeitos falantes demonstram sua classe social a partir de sua fala também. Do mesmo modo, não se pode esquecer que algumas variantes típicas de variedades 
sociais surgem motivadas por variantes rurais, isto é, variação diatópica transformando-se em variação diastrática.

De acordo com Bortoni-Ricardo (2011[1985], p. 22), "a maior parte dos traços não padrão da língua caracterizam uma estratificação gradual e não descontínua". Seguindo essa linha de pensamento, Wolfram e Fasold (1974 apud BORTONI-RICARDO, 2011[1985], p. 22-23) afirmam que:

\begin{abstract}
As variáveis que são diagnósticos sociais para uma dada população não se correlacionam com status social da mesma forma. Diferenças na descontinuidade da correlação nos levaram a distinguir entre o que temos chamado estratificação descontínua/[abrupta] e gradual. A estratificação gradual refere-se a um aumento progressivo na frequência de ocorrências de uma variante quando associada a vários grupos sociais... [quando] nenhum desses grupos mostra uma frequência significativamente maior e discrepante dos outros... Mas há outras variáveis que indicam uma descontinuidade entre grupos sociais contíguos [...] no caso dessa última estratificação, encontram-se padrões bem definidos de correção em termos das principais classes sociais; já a estratificação gradual não revela a mesma distribuição descontínua.
\end{abstract}

Assim, dito de forma sucinta, os traços graduais dizem respeito a usos linguísticos que podem ser alocados em quaisquer polos dos continua aludidos acima, a saber, situações pouco e muito monitoradas; nos falares rurais e nos urbanos; na fala de escolarizados e de analfabetos. Já os traços descontínuos referem-se, ao contrário, aos que, devido à valoração social negativa que carregam, são utilizados em algumas situações e, nesse caso, os primeiro item dos pares ilustrados anteriormente as ilustram (situações pouco monitoradas, nos falares rurais e na fala de pessoas pouco escolarizadas). No quadro seguinte, resume-se em linhas gerais, o pensamento de Bortoni-Ricardo (2005) sobre os traços graduais e descontínuos.

Quadro 1: Particularidades dos traços graduais e descontínuos

Quadro 1: Particularidades dos traços graduais e descontínuos
\begin{tabular}{|c|c|}
\hline TRAÇOS GRADUAIS & TRAÇOS DESCONTÍNUOS \\
\hline Típicos de todas as variedades & Típicos das variedades rurais \\
\hline $\begin{array}{c}\text { São estigmatizados em menor grau pela } \\
\text { sociedade urbana (grosso modo, não gera } \\
\text { estigma) }\end{array}$ & $\begin{array}{c}\text { São estigmatizados em maior grau pela sociedade } \\
\text { urbana }\end{array}$ \\
\hline
\end{tabular}

Diante dessas duas marcantes características, Bortoni-Ricardo (2004, p. 54) classifica alguns itens em traço gradual e traço descontínuo, explicando a classificação e esclarecendo que é preliminar, uma vez que para uma classificação mais definitiva é necessário conhecer mais as características do português brasileiro (quadro 2).

Quadro 2: Análise de palavras em traço gradual ou descontínuo

\begin{tabular}{|c|c|c|c|}
\hline No $^{\circ}$ & EXEMPLO & TRAÇO GRADUAL & TRAÇO DESCONTÍNUO \\
\hline 01 & Inté & & XXXXXX \\
\hline
\end{tabular}




\begin{tabular}{|l|c|c|c|}
\hline 02 & limoero & XXXXXX & \\
\hline 03 & prantei & & XXXXXX \\
\hline 04 & artura & XXXXXX & \\
\hline 05 & Ocê & XXXXXX & XXXXXX \\
\hline 06 & ponhei & XXXXXX & XXXXXX \\
\hline 07 & dos vento & XXXXXX & \\
\hline 08 & Sor & XXXXXX & XXXXXX \\
\hline 09 & dexei & & XXXXXX \\
\hline 10 & Tive & & XXXXXX \\
\hline 11 & dibaXo & & \\
\hline 12 & uma foia & & \\
\hline 13 & percisá & & \\
\hline 14 & Muié & & \\
\hline 15 & dispois & & \\
\hline
\end{tabular}

Fonte: Bortoni-Ricardo (2004, p. 54).

Percebe-se que, dos exemplos apresentados, a maior ênfase dada pela autora concerne a fenômenos fonético-fonológicos. Nenhum representa a concordância verbal, por exemplo, embora seja um tema marcado socialmente, tendo optado a autora por trazer exemplo da concordância nominal variável. Bortoni-Ricardo (2008), todavia, discute a significação social da concordância verbal, em outros trechos, e responde à seguinte questão: a variação na concordância verbal é um traço gradual ou descontínuo?

A autora demonstrou que alunos universitários notam a falta de flexão na $3^{a}$ pessoa do plural (P6), enquanto os alunos da $6^{a}$ série não. Além disso, concluiu que a percepção de traço gradual e descontínuo varia a depender da frequência da regra e que em alguns casos trata-se de um traço gradual e em outros, de traços descontínuos. Nos ambientes em que é mais notada e menos frequente, como no ambiente universitário, a falta de concordância é, sem dúvida, um traço descontínuo.

Sobre o uso da concordância verbal não padrão com a primeira e terceira pessoas do plural, isto é, sobre o uso da variante sem marcas explícitas de plural, podemos afirmar que essas ainda se constituem um caso de estereótipo sociolinguístico, ${ }^{6}$ em comunidades urbanas, letradas e em contextos monitorados, sendo, pois, um traço descontínuo, notadamente nos contextos linguísticos mais salientes, como, por exemplo, quando a forma verbal está próxima do sujeito e é mais saliente fonicamente, contextos amplamente apontados como favorecedores da marcação explícita de plural. Essas são questões relacionadas aos estudos de percepção sociolinguística e que podem se valer da saliência sociocognitiva

\footnotetext{
${ }^{6}$ Por estereótipo, usamos a conceituação de Labov (2008 [1972], p.210-212), entendendo que os falantes de maior status social na comunidade de fala rejeitam uma mudança, estigmatizando a forma inovadora, dando início a mudanças vindas de cima, adquirindo aquela forma o caráter de estereótipo.
} 
como fator explanatório, como bem explicitam Freitag (2018) e Freitag, Cardoso e Pinheiro (2018), mas que, por ora, foge ao escopo deste trabalho.

Os resultados apresentados nas tabelas 1 e 2 demonstram, por exemplo, que o uso variável da concordância verbal é bastante diferenciado a depender do nível de escolaridade dos falantes, sendo importante para demonstrar o hiato que há entre as normas cultas e populares.

Tabela 1: Aplicação da regra padrão de concordância verbal com P4 segundo a variável escolaridade do informante no português feirense

\begin{tabular}{l|l|l|l}
\hline Escolaridade & Ocorrências/ total & Frequência & Peso Relativo \\
\hline Baixa ou nenhuma & $22 / 40$ & $55 \%$ & .000 \\
\hline Superior & $111 / 112$ & $99.1 \%$ & .992 \\
\hline Total de ocorrências & $133 / 152$ & $87.5 \%$ & \\
\hline
\end{tabular}

Fonte: Araújo (2016, p. 37).

Tabela 2: Uso da variante não padrão da concordância verbal com a terceira pessoa do plural na fala de Feira de

\begin{tabular}{l|c|c}
\hline & $\mathbf{N}^{0}$ de aplic/total & Percentual \\
\hline Concordância não padrão na fala popular & $989 / 1310$ & $75.5 \%$ \\
\hline Concordância não padrão na fala culta & $40 / 659$ & $6.1 \%$ \\
\hline
\end{tabular}

Fonte: Araújo (2014, p. 244) - adaptada.

Como se depreende a partir dos resultados expostos nas tabelas 1 e 2, a escolaridade é uma variável muito atuante no uso da concordância verbal. Nessa perspectiva, a questão que se coloca é como o professor vai trabalhar as normatizações de usos linguísticos. Geralmente, essa questão perpassa pelo viés do preconceito linguístico. Na próxima seção, discorremos sobre essas questões.

\section{Diversidade linguística e escola}

Nos Estados Unidos, a Sociolinguística, desde o seu surgimento, preocupou-se com "o desempenho escolar de crianças provenientes de diferentes grupos étnicos ou redes sociais." (BORTONIRICARDO; FREITAS, 2009, p. 218), tanto na sua vertente quantitativa quanto na qualitativa. No Brasil, não obstante a presença do campo da Sociolinguística Educacional, ainda se vê poucos avanços nessa área, conforme assinala Freitag (2016, p.458): "O impacto educacional advindo da abordagem sociolinguística de orientação variacionista ainda não se faz presente na sociedade brasileira do mesmo modo como aconteceu nos Estados Unidos".

A Sociolinguística Educacional está voltada ao desenvolvimento de práticas pedagógicas que permitam a reflexão sobre a língua, no sentido de problematizar o objeto de estudo das aulas de português. Segundo Bortoni-Ricardo (2005, p. 15), os professores deveriam ter como foco em suas aulas o desenvolvimento da competência comunicativa dos estudantes, conscientizando-os das implicações sociais de suas escolhas linguísticas. 
Nesse sentido, é interessante pontuar algumas questões: "a escola não pode ignorar as diferenças sociolinguísticas", mas até que ponto não ignora? Sabe-se que, na escola, há a predominância do trabalho com a gramática normativa, ensinando-se o padrão, o que deve, sim, acontecer, mas ao trabalhar com os conceitos de "certo" e "errado", a escola impõe que o que há na gramática é o que é válido e tudo aquilo que não é encontrado nos compêndios gramaticais está errado. Acontece que a gramática não é a língua e ela, então, não pode dar conta, e não dá, de todas as variações que a língua sofre e de todas as mudanças pelas quais a língua passou.

Assim, ratifica-se que as normas cultas e populares devem ser respeitadas e utilizadas em contextos específicos, como defendido por Soares (2017[1985]) e Bortoni-Ricardo (2005).

Diante desse contexto, percebe-se que a gramática normativa, o ensino de Língua Portuguesa e os livros didáticos avançaram muito pouco quanto à problematização da língua. O papel da Sociolinguística Educacional, nesse sentido, é contribuir com práticas que permitam um ensino reflexivo da norma culta, deixando claro aos professores e, por meio deles, aos alunos, que a língua deve ser considerada em uso, a partir da competência comunicativa dos falantes, levando em consideração a heterogeneidade linguística. (FARACO, 2008)

Vieira (1995) afirma que é necessário que o ensino de Língua Portuguesa se ancore nas pesquisas sociolinguísticas e destaca a pesquisa de Lemle e Naro (1977 apud VIEIRA, 1995), na qual os autores propõem caminhos para o ensino da concordância verbal, os quais são destacados a seguir:

Dar ênfase aos casos em que mais se diferem as normas culta e popular.

I)

Os exercícios devem enfatizar os verbos regulares no presente e no imperfeito do

II) indicativo pela pouca diferença fônica entre singular e plural.

Os exercícios devem privilegiar sujeitos pospostos e distantes do verbo.

III)

Partir de casos mais simples para o aluno para, em seguida, apresentar casos mais

IV) complexos. (LEMLE; NARO, 1977 apud VIEIRA, 1995, p. 140-141).

A propósito, na modalidade oral da língua portuguesa do Brasil, como demonstram os dados do projeto NURC (Projeto Norma Urbana Culta), amplamente coletados em cinco capitais brasileiras, falantes com nível superior completo - em situações de entrevistas, locuções formais ou de diálogos - não seguem à risca as prescrições gramaticais. Usos vernaculares como (a) "Eu conheço ele muito bem", (b) "Me passe o açúcar", (c) "Tem muita gente lá fora" mostram que nem mesmo pessoas com nível superior de escolaridade utilizam inteiramente a norma-padrão, ou seja, não seguem totalmente as prescrições da gramática normativa. Por outro lado, não se pode negar que as dificuldades em relação ao processo de ensino-aprendizagem de língua primeira serão mais acentuadas para estudantes que têm como sua norma linguística o falar popular; fala-se, principalmente, dos alunos provenientes da zona rural e daqueles que habitam a periferia dos grandes centros urbanos.

De modo geral, é possível detectar que as principais dificuldades em relação ao ensino de português para estudantes da zona rural são: a existência de um currículo escolar urbanocêntrico; a 
insensibilidade com o trato das especificidades do alunado do campo e a falha no trato com a diversidade cultural e linguística.

Percebe-se, também, que, apesar de alguns avanços alcançados na área da Educação do campo, como a existência dos Art. 26 e 28 da Lei 9394/96, ainda há muito a ser realizado para que, de fato, o ensino de português constitua-se uma atividade que venha a se tornar fundamental para 0 desenvolvimento da competência comunicativa dos educandos, partindo-se da realidade sociocultural dos estudantes.

\section{Considerações finais}

Ao término deste artigo, afirmamos que diferentemente dos alunos que vêm de famílias letradas, cuja variedade de língua é mais próxima da que é ensinada na escola, os alunos de classes mais desfavorecidas, além de terem que, praticamente, aprender uma nova língua, não têm sua variedade de língua valorizada e, muito menos, colocada como objeto de estudo na sala de aula. Desse modo, as dificuldades que os alunos do campo, por exemplo, apresentam em relação a atividades linguísticas são tratadas como se estas ocorressem em função de falta de capacidade, quando, na verdade, tais dificuldades estão relacionadas ao desconhecimento da escola em relação às variedades linguísticas existentes no Brasil.

Nesse sentido, é fundamental que o conhecimento que vem sendo acumulado ao longo de mais de quarenta anos de pesquisa sobre a variação linguística seja, de fato, socializado entre os professores de Língua Portuguesa, para que estes utilizem tal conhecimento em benefício do ensino-aprendizagem de língua portuguesa.

Concluímos, ainda, que deve ser estimulado o surgimento de iniciativas que visem à formação continuada de professores do campo e da cidade no semiárido baiano, com o respeito às manifestações culturais, priorizando-se o desenvolvimento de habilidades e de valores.

Assim, como expõem Ribeiro e Lacerda (2013, p. 95):

Em função da urbanização e dos aspectos a ela associados, a cultura rural passou a ser, gradativamente, desvalorizada. O ideário de que a "civilização" estava nos centros urbanos favoreceu o desprestígio das comunidades rurais, como se percebe até na atualidade. Essa desvalorização e esse desprestígio se refletem na língua.

Entretanto, é preciso compreender que o campo, atualmente, é um espaço ressignificado que mantém diretas relações com a cidade, não só comerciais, mas culturais e linguísticas. Essa questão tem que ser considerada no trabalho de ensino-aprendizagem de Língua Portuguesa nas escolas. 


\section{Referências}

ARAúJO, Silvana Silva de Farias. Nosso, da gente e de nós: um estudo sociolingüístico da expressão de posse no português rural afro-brasileiro. Dissertação (Mestrado em Letras) Instituto de Letras, Universidade Federal da Bahia, Salvador, 2005.

ARAUJO, Silvana Silva de Farias. Concordância verbal no português falado em Feira de Santana-BA: sociolinguística e sócio-história do português brasileiro. Tese (Doutorado). Universidade Federal da Bahia, Instituto de Letras, Salvador, 2014.

ARAÚJO, Silvana Silva de Farias. A concordância verbal nos continua sociolinguísticos do português brasileiro e do luandense. Interdisciplinar: Revista de Estudos em Língua e Literatura, v. 24, p. 25-46, 2016.

BORTONI-RICARDO, Stella Maris. Educação em língua materna: a sociolinguística na sala de aula. São Paulo: Parábola Editorial, 2004.

BORTONI-RICARDO, Stella Maris. Nós cheguemu na escola, e agora?: sociolinguística e educação. 2. ed. São Paulo: Parábola Editorial, 2005.

BORTONI-RICARDO, Stella Maris. Do campo para a cidade: estudo sociolinguístico de migração e redes sociais. Tradução de Stella Maris Bortoni-Ricardo e Maria do Rosário Rocha Caxangá. São Paulo: Parábola Editorial, 2011[1985].

BRASIL. Lei de Diretrizes e Bases - Lei 9394/96 | Lei no 9.394, de 20 de dezembro de 1996. Disponível em: < https://presrepublica.jusbrasil.com.br/legislacao/109224/lei-de-diretrizes-e-bases-lei-9394-96\# art-26>. Acesso em: 13 out. 2018.

CALLOU, Dinah. Gramática, variação e normas. In: VIEIRA, Silvia Rodrigues; BRANDÃO, Silvia Figueiredo (Org.). Ensino de gramática: descrição e uso. 2. ed. São Paulo: Contexto, 2016, p. 13-29.

FARACO, Alberto. Norma culta brasileira: desatando alguns nós. São Paulo: Parábola Editorial, 2008.

FREITAG, Raquel. Sociolinguística no/do Brasil. Cadernos de Estudos Linguísticos (UNICAMP), v. 58, p. 445-460, 2016.Disponível em: <https://periodicos.sbu.unicamp.br/ojs/index.php/cel/article/view/8647170 >. Acesso em: 22. Nov. 2018

FREITAG, Raquel. Saliência estrutural, distribucional e sociocognitiva. Acta scientiarum. Language and culture (impresso), v. 40, p. 41173-10, 2018. Disponível em: < http://www.periodicos.uem.br/ojs/index.php/ActaSciLangCult/article/view/41173/pdf>. Acesso em 26.nov.2018. FREITAG, Raquel; CARDOSO, Paloma Batista; PINHEIRO, Bruno Felipe Marques. Saliência na conservação de /d/ no segmento /ndo/: efeitos sociais e estilísticos. Gragoatá (UFF), v. 23, p. 654-678, 2018. Disponível em: http://www.gragoata.uff.br/index.php/gragoata/article/view/1123/738. Acesso em 27.nov.2018.

GNERRE, Maurízio, Linguagem, escrita e poder. 3. ed. São Paulo: Martins Fontes, 1985.

LABOV, William. Padrões sociolingüísticos. Tradução Marcos Bagno, Maria Marta Pereira Scherre, Caroline Rodrigues Cardoso. São Paulo: Parábola Editorial, 2008.

LUCCHESI, Dante. A questão da formação do português popular do Brasil: notícia de um estudo de caso. A cor das Letras, Feira de Santana, 3, p. 73-100, 1999.

LUCCHESI, Dante. A variação na concordância de gênero em uma comunidade de fala afro-brasileira: novos elementos sobre a formação do português popular do Brasil. Tese (Doutorado em Língua Portuguesa). Faculdade de Letras. Universidade Federal do Rio de Janeiro, 2000.

LUCCHESI, Dante. As duas grandes vertentes da história sociolingüística do Brasil (1500-2000). DELTA. São Paulo. v.17, n.1, p. 97-132, 2001.

LUCCHESI, Dante. Norma lingüística e realidade social. In: BAGNO, Marcos (Org.). Lingüística da norma. São Paulo: Edições Loyola, 2002, p. 63-92.

LUCCHESI, Dante. Língua e sociedade partidas: a polarização sociolinguística no Brasil. São Paulo: Contexto, 2015.

LUCCHESI, Dante. A periodização da história sociolinguística do Brasil. DELTA, São Paulo, v. 33, n. 2, p. 347382, 2017

LUCCHESI, Dante; BAXTER, Alan; RIBEIRO, Ilza (Org). O português afro-brasileiro. Salvador: EDUFBA, 2009.

MATTOS E SILVA, Rosa Virgínia. Português brasileiro: raízes e trajetórias. Discursos, 3, p. 75-92, 1993.

MATTOS E SILVA, Rosa Virgínia. Da sócio-história do português brasileiro para o ensino do português no Brasil hoje. Revista da FAEBA, Salvador, n. 15, p. 23-36, 2001.

MATTOS E SILVA, Rosa Virgínia. Caminhos da lingüística histórica: ouvir o inaudível. São Paulo: Parábola Editorial, 2008.

MATTOS E SILVA, Rosa Virgínia. Contradições no ensino de português: a língua que se fala $X$ a língua que se ensina. 8. ed. São Paulo: Contexto, 2017[1995].

NARO, Anthony Julius; SCHERRE, Maria Marta Pereira. Concordância variável em português: a situação no Brasil e em Portugal. In: NARO, Anthony Julius; SCHERRE, Maria Marta Pereira. Origens do português brasileiro. São Paulo: Parábola Editorial, 2007.

RIBEIRO, Patrícia Rafaela Otoni; LACERDA, Patrícia Fabiane Amaral da Cunha. Variação, Mudança e não mudança linguística: ressignificando o conservadorismo linguístico no português do Brasil. Revista LinguíStica / Revista do Programa de Pós-Graduação em Linguística da Universidade Federal do Rio de Janeiro. Volume 9, número 2, dezembro de 2013. ISSN 1808-835X 1. [http://www.letras.ufrj.br/poslinguistica/revistalinguistica]. SOARES, Magda. Linguagem e escola: uma perspectiva social. 18. ed. São Paulo: Contexto, 2017 [1986]. 
SOUSA, Nilton Carlos Carmo. A concordância verbal no continnum rural-urbano: uma análise sociolinguística da fala de estudantes do município de Tucano-BA. Dissertação (Mestrado em Estudos Linguísticos) - Pós-Graduação em Estudos Linguísticos, Universidade Estadual de Feira de Santana, Feira de Santana. (no prelo)

VIEIRA, Silvia Rodrigues. Variação em dialetos populares do norte fluminense, 163 f. Dissertação (Mestrado em Língua Portuguesa) - Pós-Graduação em Letras da Universidade Federal do Rio de Janeiro, Rio de Janeiro, 1995. 